\title{
Jaume Aurell y otros, Comprender el pasado. Una historia de la escritura y el pensamiento histórico. Madrid: Ediciones Akal, 2013, 493 págs.
}

Esta obra colectiva de Jaume Aurell, ${ }^{1}$ Catalina Balmaceda, ${ }^{2}$ Peter Burke ${ }^{3}$ y Felipe Soza, ${ }^{4}$ destinada especialmente para público de habla hispana y portuguesa, ${ }^{5}$ constituye un valiosísimo aporte a la Historia de la Historiografía porque ofrece a los investigadores una síntesis para aproximarse al conocimiento de la escritura y el pensamiento histórico a lo largo de la historia y se transforma en un accesible y amplio manual para estudiantes de historia, tanto por la organización bien estructurada del libro, el uso de epígrafes, referencias a los historiadores representativos de cada período y breves citas de sus textos históricos, como por los esquemas de contenido, comentarios bibliográficos al final de cada capítulo y una selección final de historiadores y obras históricas. Bien podríamos afirmar que esta obra expresa en sí misma lo que Pierre Bourdieu denominara un capital cultural en estado objetivado, aunque como manual de estudio podría haber contribuido un aparato crítico más profundo que refiera a las distintas interpretaciones de los estudios específicos sobre historiadores o corrientes historiográficas. ${ }^{6}$ Aun así, esta sistematización evidencia el crecimiento progresivo que han experimentado los estudios historiográficos en las últimas décadas, así como la instauración de la Historia de la Historiografía como área específica dentro del campo de la historia y como asignatura disciplinar en los planes de estudios universitarios. ${ }^{7}$

Según la propuesta de los autores, esta historia de la historiografía es considerada como una "verdadera historia intelectual" en tanto que no atiende únicamente al contenido interno de los textos históricos sino que busca comprenderlos en su interrelación con el contexto histórico, cultural, social y político. En este sentido, estamos convencidos de que la forma más fructífera de encarar estudios de tipo historiográfico hoy en día sea atendiendo a cuestiones propias de la historia intelectual.

Catalina Balmaceda, se ocupa, en los primeros dos capítulos de la obra del estudio de la historiografía de la Antigüedad clásica (Grecia y Roma) y tardía (historiografía

\footnotetext{
${ }^{1}$ Profesor de Teoría de la Historia en la Universidad de Navarra (España), medievalista e historiógrafo reconocido por sus investigaciones y publicaciones sobre medievalismo contemporáneo.

${ }^{2}$ Profesora de Historia Clásica en el Instituto de Historia de la Pontificia Universidad Católica de Chile, historiadora especializada en historia intelectual romana, filosofía política e historiografía grecolatina.

${ }^{3}$ Emeritus Professor y Life Fellow del Emmanuel College (Cambridge) reconocido internacionalmente por sus prolíferos estudios sobre historiografía.

${ }^{4}$ Licenciado en Historia y en Filosofía por la Pontificia Universidad Católica de Chile, dedicado al estudio de la historiografía antigua y contemporánea y de las relaciones entre historia y filosofía.

${ }^{5}$ Obras recientes, pero en inglés, serían las de John Burrow, A History of Histories: Epics, Chronicles, Romances and Inquiries from Herodotus and Thucydides to the Twentieth Century (Londres: Penguin Books, 2007); Daniel Woolf, A Global History of History (Cambridge: Cambridge University Press, 2011); y la obra colectiva The Oxford History of Historical Writing, 5 vols. (Oxford: Oxford University Press, 2011-2012).

${ }^{6}$ Pierre Bourdieu, "Los Tres Estados del Capital Cultural”, Sociología, 5, (1979): 11-17.

${ }^{7}$ Para el caso español una breve síntesis de este proceso puede verse en Miquel A. Marín Gelabert, reseña de La escritura de la memoria; de los positivismos a los posmodernismos, por Jaume Aurell, Revista de Historiografía, vol. 2, 2 (1/2005): 187-194.
} 
cristiana y bizantina). El análisis encara los aspectos principales de la historiografía griega y romana aunque la autora no parece dejar suficientemente claro que la finalidad de estas historiografías fue establecer fundamentalmente un parámetro para determinar lo bueno y lo malo de las acciones humanas, algo que antes venía impuesto por el relato mítico y que ahora se tornaba necesario determinar por el pensamiento lógico del hombre. La historia se transformó así, para los escritores griegos y romanos, en una herramienta clave para lo que podríamos llamar la fabricación del bien y del mal. ${ }^{8}$ Esta utilidad se vio reforzada durante la Antigüedad tardía (Capítulo 2) por el parámetro del bien y del mal establecido según la doctrina judeocristiana. Reconoce así Balmaceda que la postura de San Agustín, en su obra Ciudad de Dios, tenía por fin "mostrar cuál es el supremo bien y cuál el supremo mal". ${ }^{10}$

Pero no señalamos este punto pretendiendo remarcar simplemente la importancia de la retórica en la historiografía de la antigüedad clásica, como lo han hecho T. P. Wideman y A. Woodman, ${ }^{11}$ sino retomar la discusión acerca de las relaciones entre contenido y forma en la escritura de la historia, algo que Balmaceda parece descartar: "La retórica, el arte de hablar bien, como instrumento o como arma es en sí algo neutro, todo depende de cómo y para qué se utilice". ${ }^{12}$

A nuestro entender, el aporte más interesante de Balmaceda (que el lector encontrará entre las páginas 64 y 68) es el haber matizado las generalizaciones comunes sobre el carácter universal, apologético, lineal y providencialista de la historiografía cristiana. $^{13}$

Por su parte, el capítulo de Jaume Aurell destaca por ofrecer una mirada de conjunto sobre la historiografía medieval entre los siglos IX y XV atendiendo a la naturaleza de la escritura histórica, los diferentes géneros históricos practicados y la delimitación y caracterización de tres fases durante el período. El análisis adquiere toda su significatividad a partir del planteamiento teórico que realiza Aurell y que le permite superar algunas de las debilidades más comunes en los estudios actuales de historiografía medieval. Según señala, "una de las claves para la correcta interpretación de la historiografía medieval es una aproximación conjunta a la lógica interna del texto y al contexto social y político del que ha surgido"; ${ }^{14}$ es decir, el abordaje de lo que G. M. Spiegel ${ }^{15}$ y N. F. Partner ${ }^{16}$ han denominado la "lógica social del texto" y que se refiere al estudio de la dimensión linguiística, narrativa y discursiva del texto histórico -

\footnotetext{
${ }^{8}$ Véase Antonio Valdecantos, La fábrica del bien (Madrid: Síntesis, 2008).

${ }^{9}$ Para la autora, aunque San Agustín no pueda ser considerado como un historiador genuino, sí desarrolló un pensamiento histórico muy influyente sobre la comprensión e interpretación de la historia. C. Balmaceda, "La Antigüedad tardía: la historiografía cristiana y bizantina", en Comprender el pasado, ed. Jaume Aurell y otros (Madrid: Akal, 2013), 72-73.

${ }^{10}$ Ibid., 64.

11 T. P. Wideman, Clio's Cosmetics: Three Studies in Greco-Roman Literature (Leicester: Leicester University Press, 1979); A. Woodman, Rhetoric in Classical Historiography: four studies (London and New York: Routledge, 1988).

${ }^{12}$ C. Balmaceda, "La Antigüedad clásica", 28. Cfr. Hayden White, The Content of the Form: Narrative Discourse and Historical Representation (Baltimore: The Johns Hopkins University Press, 1987).

${ }^{13}$ Confróntese con la postura de R. G. Collingwood, Idea de la Historia (México: F.C.E., 1952), 56-59.

${ }^{14}$ Jaume Aurell, "La historiografía medieval: siglos IX-XV", en Comprender el pasado, 98.

${ }^{15}$ G. M. Spiegel, The Past as Text: Theory and Practice of Medieval Historiography (Baltimore, 1997).

${ }^{16}$ N. F. Partner, Writing Medieval History (London: Hodder Arnold, 2005).
} 
lo que viene a constituir su lógica interna - en relación a su dimensión contextual entendida en un sentido social. ${ }^{17}$

El capítulo de Peter Burke, que abarca el período del Renacimiento a la Ilustración, se detiene en algunas cuestiones en relación con los primeros intentos por parte de los historiadores por determinar una periodización general de la historia del mundo y ofrecer una "explicación histórica" que sustentara la utilidad política de sus escritos históricos y que permitiera generalizaciones y análisis más sofisticados, aunque Burke reconoce que será recién en obras del siglo XVIII que algunos historiadores "explicarán las cosas, tanto en términos que hoy calificaríamos de estructurales como en términos de motivación individual". ${ }^{18}$

Lo más interesante del estudio de Burke es que analiza "la historia de las obras históricas desde el punto de vista del lector y del autor, de la audiencia y de la autoría". ${ }^{19}$ Atendiendo a qué se leía, quién lo leía y cómo se leía, Burke ofrece una visión particular sobre la escritura histórica que reconoce formas de lecturas distintas a la nuestra como la lectura retórica, la lectura moral, la lectura política y la lectura alegórica, cada una con efectos específicos sobre las interpretaciones que podían hacerse de las obras históricas del período. ${ }^{20}$

El breve capítulo dedicado a las historiografías islámica y china, escrito también por Burke, si bien constituye un aporte valioso para que el lector tenga al menos una noción general de sus particularidades no representa un análisis profundo de las mismas sino que posibilita una somera comparación entre estas dos tradiciones historiográficas orientales y con la occidental para identificar algunos aspectos en común. ${ }^{21}$

A la hora de analizar las historiografías del siglo XIX y XX, Jaume Aurell y Peter Burke unen saberes en el intento de sistematizar y comprender los últimos doscientos años de historia de la escritura y el pensamiento histórico.

El capítulo 6 se enfoca en el siglo XIX, el denominado "siglo de la historia", en el que diversos movimientos intelectuales - como el romanticismo, el historicismo, el marxismo y el positivismo - ofrecieron diferentes vías teórico-metodológicas para que la historia pudiera adquirir verdadero status de "ciencia", según los cánones decimonónicos. Aurell y Burke recorren así las escuelas nacionales más importantes del período -alemana, francesa, británica y española- concluyendo que esta evolución de la historiografía del siglo XIX - especialmente en la francesa - "demuestra, una vez más, la continua interrelación que se produce entre el texto y el contexto histórico". ${ }^{22}$

\footnotetext{
${ }^{17}$ Esta postura representa un esfuerzo por superar la deshistorización masiva del texto que provocaron las teorías posmodernistas sin retornar a concepciones metodológicas previas al estructuralismo. Véase G. Spiegel, "Historia, historicismo y lógica social del texto en la Edad Media", en Historia y Literatura, comp. Francoise Perus (México: Instituto Mora, 1994), 123-161.

${ }^{18}$ Peter Burke, "Del Renacimiento a la Ilustración”, en Comprender el pasado, 151.

${ }^{19}$ Ibid., 170. Cuestión que los autores proponían en el prólogo de la obra pero que en los capítulos de Balmaceda y Aurell no aparecía explícitamente tratada.

${ }^{20}$ Ibid., 172-173.

${ }^{21}$ Peter Burke, "Más allá de Occidente: islam y China”, en Comprender el pasado, 196.

${ }^{22}$ Jaume Aurell y Peter Burke, "El siglo de la historia: historicismo, romanticismo, positivismo", en Comprender el pasado, 228
} 
En este capítulo quizás pueda generar confusión en el lector la identificación de una "historiografía positivista" de la que formarían parte tanto el historicismo clásico alemán - representado por Ranke - como la escuela metódica francesa - Langlois y Seignobos - y las historias alternativas de carácter económico - Henri Pirenne - o sociocultural - Jacob Buckhardt - . Aunque los autores aclaran que, si bien el término positivismo se refiere en sentido estricto a la historia practicada según el modelo de Comte, en sentido general puede referirse también a la simple idea de que "la historia es una ciencia" y a las diferentes formas de "empirismo histórico" - sentido que finalmente parecen otorgarle $-{ }^{23}$

El siglo XX ocupa la atención central de Aurell y Burke. A él dedican casi la cuarta parte del libro. Al estudiar las reacciones frente al positivismo, los autores focalizan su análisis en las propuestas historicistas que desde la filosofía de la historia elaboraron, fundamentalmente, Benedetto Croce y Robin G. Collingwood, ${ }^{24}$ a las que se sumaron interpretaciones organicistas y universales de la historia y aportes teóricometodológicos de la sociología, que posibilitaron la emergencia y difusión de la propuesta historiográfica renovadora de la "Escuela de los Annales", corriente a la que los autores dedican extensas páginas. En este punto, es clara la inclinación de los autores a destacar el aporte de Annales - y valorizar también las contribuciones de la historiografía española - en desmedro del materialismo histórico que, para los autores, sólo se revitalizó en el siglo XX por las circunstancias históricas que permitieron nuevas lecturas de los textos de Marx "siempre abiertos a nuevas interpretaciones según lo dictaminaran las necesidades de cada momento". 25

Finalmente, los autores abordan la cuestión del "posmodernismo" y la "crisis de la historia" desde la década de los años setenta de la pasada centuria. Su visión es notoriamente crítica y sostienen que "el posmodernismo está presente como una actitud teórica ante la obra y el conocimiento histórico, pero no como una verdadera y propia corriente historiográfica", aunque pueden valorarse algunos aportes para el historiador. ${ }^{26}$ A pesar de las consecuencias relativistas derivadas del posmodernismo en la historiografía, este posibilitó, ante la crisis de los grandes paradigmas historiográficos del siglo XX, la emergencia de otras propuestas de historias alternativas e intentos de síntesis o interpretaciones más generales y complejas de la historia. ${ }^{27}$

Por su parte, Felipe Soza se encarga de abordar el desarrollo de la historiografía latinoamericana en el último y más largo capítulo del libro, que por su amplitud temporal, espacial y temática bien podría ser publicado como un libro independiente aunque en el conjunto de esta obra colectiva permite establecer relaciones significativas

\footnotetext{
${ }^{23}$ Ibid., 220-221.

24 Jaume Aurell y Peter Burke, "De entresiglos a la década de los setenta: la reacción frente al positivismo", en Comprender el pasado, 241.

${ }^{25}$ Ibid., 280.

${ }^{26}$ Jaume Aurell y Peter Burke, "Las tendencias recientes: del giro lingüístico a las historias alternativas", en Comprender el pasado, 289.

${ }^{27}$ Se refieren a las nuevas nuevas historias - reiteración intencional de los autores - como ser la nueva historia cultural, la nueva historia narrativa junto a la microhistoria, la nueva historia política, la historia de la religiosidad, la historia social del lenguaje, la historia de la vida privada, la historia de género y los estudios subalternos y poscoloniales. Ibid., 330 .
} 
en el desarrollo de esta denominada "historiografía latinoamericana" 28 bajo las influencias de las escuelas historiográficas europeas. Este capítulo representa un aporte muy interesante al abordar la evolución de la historiografía en la enorme extensión territorial de Latinoamérica, ${ }^{29}$ además de que identifica y caracteriza cuatro momentos historiográficos en este proceso, que van desde las crónicas de las conquistas hasta la historiografía académica, pasando por la historiografía criolla y las historias nacionales. ${ }^{30}$

Dos cosas se podrían cuestionar a la síntesis de Soza. Primero, es cuestionable aglutinar el desarrollo de la historiografía latinoamericana durante el siglo XX como resultado de un mismo "momento historiográfico", teniendo en cuenta la variedad de interpretaciones que se dieron durante el mismo, además de las cambiantes circunstancias político-sociales que condicionaron fuertemente los escritos históricos y, más aún, porque el autor sostiene que esta nueva etapa, que comienza ya entrado el siglo XX, se manifiesta en una pérdida de la injerencia política y pública de los historiadores, en una retirada al mundo académico y en una pérdida de lectores del público general, aspectos que - sobre todo en Argentina - no se pueden evidenciar claramente hasta el retorno de la democracia en la década de los ochenta. ${ }^{31}$ En segundo lugar, es cuestionable la atribución de la renovación historiográfica latinoamericana del siglo XX principalmente a la influencia de la escuela de Annales, pues si bien menciona en un tímido párrafo la influencia del marxismo (p. 424) no reconoce ni describe el alcance que tuvieron en Latinoamérica especialmente los escritos de Antonio Gramsci. ${ }^{32}$

Por último, las breves descripciones que realizan los autores en el epílogo sobre las tendencias historiográficas que serán hegemónicas en un inmediato futuro son útiles para formarse un panorama general del estado actual de los estudios historiográficos, aunque no advierten que, al menos hasta ahora, el cambio fundamental tiene que ver con que estas tendencias no buscan proyectarse ya como una escuela o una corriente historiográfica, menos aún como un modelo hegemónico, sino que se presentan más bien como un conjunto de convergencias y preocupaciones que proceden de diversas fuentes de inspiración teórica. ${ }^{33}$

\footnotetext{
${ }^{28}$ Probablemente convendría hablar del desarrollo de la "historiografía en Latinoamérica" más que usar la categoría de "historiografía latinoamericana", teniendo en cuenta la falta de unidad entre los espacios nacionales respectivos.

${ }^{29}$ Advierte Soza que elige la denominación de Latinoamérica por ser más inclusiva territorialmente que otros términos como Hispanoamérica o Iberoamérica. Felipe Souza, "La historiografía Latinoamérica", en Comprender el pasado, 341.

${ }^{30}$ Soza fundamenta la identificación de una "historiografía criolla" en la propuesta de Antonello Gerbi (Ibid, 362). Véase Antonello Gerbi, La disputa del Nuevo Mundo. Historia de una polémica, 1750-1900 (México: F.C.E., 1982).

${ }^{31}$ Ibid., 343. Véase Elias Zeitler, "El campo historiográfico argentino en la democracia. Transición, profesionalización y renovación”, Revista Digital Estudios Históricos, 3 (diciembre, 2009), http://www.estudioshistoricos.org/edicion 3/elias-zeitler.pdf [consulta 13 septiembre, 2014].

${ }^{32}$ Para Latinoamérica véase el texto más reciente de Dora Kanoussi, comp. y ed., Gramsci en América (México: Benemérita Universidad Autónoma de Puebla-Gramsci Society-Plaza y Valdéz, 2000) y el libro de José María Aricó, La cola del diablo: Itinerario de Gramsci en América Latina (Buenos Aires, Punto Sur Editores, 1988). Para Argentina véase la obra de Raúl Burgos, Los Gramscianos Argentinos: cultura y política en la experiencia de "Pasado y Presente" (Buenos Aires: Siglo XXI Editores, 2004).

33 Véase Carlos Altamirano, "De la historia política a la historia intelectual: reactivaciones y renovaciones", Prismas, 9 (2005), http://www.historiapolitica.com/datos/biblioteca/xixaltamirano.pdf [consulta 21 octubre, 2014].
} 
Podemos concluir con certeza que esta obra constituye un indudable aporte para el conocimiento de la historia de la historiografía en estrecha relación con la historia intelectual, tanto como sistematización del saber con el fin de hacerlo más asequible a estudiantes e investigadores, como manifestación de la presencia creciente y la importancia significativa de la historia de la historiografía en los ámbitos intelectuales y académicos.

Tomás Elias Zeitler

Universidad Nacional del Nordeste (Argentina)

eliaszeitler@gmail.com

Fecha de recepción: 10 de diciembre de 2014.

Fecha de aceptación: 12 de diciembre de 2014.

Publicado: 31 de diciembre de 2014.

Para citar: Tomás Elias Zeitler, "Jaume Aurell y otros, Comprender el pasado; Una historia de la escritura y el pensamiento histórico. Madrid: Ediciones Akal, 2013, 493 págs.", Historiografias, 8 (julio-diciembre, 2014): pp. 163-168.

http://www.unizar.es/historiografias/historiografias/numeros/8/zeitler.pdf 